\title{
Linkage analysis of neurofibromatosis (von Recklinghausen disease)
}

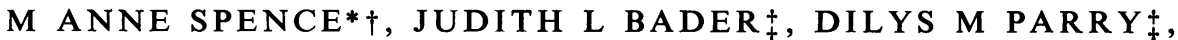 \\ L LEIGH FIELD*, STEVE J FUNDERBURK*, ALLAN E RUBENSTEIN, \\ PRISCILLA A GILMAN+, AND ROBERT S SPARKES*\|ף \\ From the Departments of *Psychiatry, $\dagger$ Biomathematics, IIMedicine, and $\mid$ Pediatrics, UCLA School of \\ Medicine, Los Angeles, California; $\ddagger_{+}$the Clinical Epidemiology Branch, NationalCancer Institute, \\ Bethesda, Maryland; and §the Department of Neurology, Mount Sinai School of Medicine, New York, \\ USA.
}

SUMMARY Linkage analysis of 28 genetic markers was undertaken in 108 subjects from 11 families with well-documented, classic, peripheral neurofibromatosis. Fifty-four persons were affected in one four-generation family, seven three-generation families, and three two-generation families. Lod scores were calculated using the standard LIPED programme for 49 combinations of $\theta_{\text {male }}$ and $\theta_{\text {female }}$ from 0.01 to $0 \cdot 50$. Lod scores excluded close linkage with 16 markers, including most tested on chromosome 1 and HLA on chromosome 6, and were inconclusive for 12 markers, including the secretor locus, closely linked to myotonic dystrophy. Analysis of five informative families resulted in a lod score of $+2 \cdot 2$ for close linkage with GC on chromosome 4 . However, the lod score for GC in the one additional informative family was negative, so that the final interpolated maximum was $\mathrm{Z}=0.89$ for $\hat{\theta}_{\text {male }}=0.03, \hat{\theta}_{\text {female }}=0.28$. Further studies are needed to evaluate this suggestion of linkage and possible genetic heterogeneity.

Neurofibromatosis (NF), von Recklinghausen disease, is an autosomal dominant disorder which occurs once in 3000 live births. ${ }^{1}$ Although NF has variable phenotypic expression, classic minimal diagnostic features include six or more pigmented skin macules (café-au-lait spots), each at least $1.5 \mathrm{~cm}$ in greatest diameter, or multiple benign tumours (neurofibromas) occurring along peripheral nerves in the skin or internally. ${ }^{1}$ Other severe clinical problems, including cancer, may develop in nearly all organ systems. ${ }^{1}$

Despite the high frequency of NF, only two published reports have evaluated markers for genetic linkage in affected families. The co-segregation of NF and myotonic dystrophy (MD) in one family suggested the possibility of linkage between these two loci. ${ }^{2}$ In seven other families, NF showed no evidence of close linkage with HLA. ${ }^{3}$ Using 28 genetic markers we performed linkage analysis on 11 families with well-documented NF.

\section{Materials and methods}

Our families with NF were ascertained through four

Received for publication 25 October 1982. Accepted for publication 10 February 1983. sources: the Clinical Epidemiology Branch, National Cancer Institute (seven families: NCI 0987, 1008, 1092, 1159, 1282, 1320, 1327 [UCLA NF: 001, 002, $003,005,015,012$, and 013 respectively]); the UCLA Genetics Counselling Clinic (two: N002, NF004); the Department of Neurology, Mount Sinai School of Medicine (one: NCI 1424 [NF011]); and the Pediatric Oncology Division, Johns Hopkins Hospital (one: NCI 1169 [NF008]). Families were considered suitable for study if they had (a) affected subjects in at least two generations, (b) at least three affected subjects, (c) all participants (or parents of minors) willing to sign informed consent, and (d) the ability to travel to our clinics or assemble centrally for clinical examination and phlebotomy. We examined and drew blood specimens from 108 persons, including 54 affected subjects in one fourgeneration family, seven three-generation families, and three two-generation families. NF was diagnosed using standard clinical criteria. ${ }^{1}$ With the exception of two obligate gene carriers (see below), the phenotype of any person in whom the diagnosis of NF was equivocal was coded as unknown; there were two such persons, one under the age of 15 years. To minimise the possibility of genetic heterogeneity, 
we limited this study to families with classic 'peripheral' NF. In particular, we excluded families in which acoustic neuroma had been diagnosed in any subject. Familial acoustic neuroma, sometimes associated with one or more café-au-lait spots and an occasional peripheral neurofibroma, has been referred to as 'central' NF. ${ }^{4}$ However, for the present study, it was considered distinct from the peripheral form of the disease.

Using standard laboratory techniques, ${ }^{5-7} 28$ gene markers were analysed for each subject. HLA typing was performed by Dr Paul Terasaki, UCLA, for five families and by the Naval Medical Research Institute and Uniformed Services University for the Health Sciences, Bethesda, Maryland, for the rest. All other markers were typed in the laboratory of Dr Robert $S$ Sparkes, UCLA. GC typing was done by isoelectric focusing. ${ }^{8}$ Determination of secretor status was made from the Lewis blood type. ${ }^{9}$ Only three subjects were Lewis $(a-b-)$ and, therefore, of ambiguous secretor status.

For the linkage analysis we assumed that NF is a single gene disorder with autosomal dominant inheritance and an allele frequency of 0.001 . We chose a penetrance value of 0.95 because a few well-documented clinical instances of reduced penetrance (obligate gene carriers without the NF phenotype) have been reported. ${ }^{10}$ Our study population included two such persons: (a) a 50-yearold woman whose brother, son, and grandson were unequivocally affected with NF, and (b) a 45 -year-old man with an affected mother and daughter. Neither of these had any clinical stigmata of NF. All other obligate carriers in the 11 families met standard clinical criteria for the diagnosis of NF. The computer algorithm assigns affected genotypes to obligate carriers, irrespective of phenotype, while other subjects with an unaffected phenotype are treated as having a small probability of carrying the NF allele.

Lod scores were calculated for each pedigree for all informative markers using the LIPED programme $^{11}$ for a $7 \times 7$ matrix of recombination fractions with $\theta_{\text {male }}, \theta_{\text {female }}=0.01,0.05,0.1,0.2$, $0 \cdot 3,0.4$, and $0 \cdot 5$. Lod scores were then summed across pedigrees.

\section{Results}

For 16 genetic markers, the lod scores provided statistically significant evidence against linkage (lod $\leq-2 \cdot 0)$ for at least some values of $\theta$ (table 1). Results are given only for equal male and female recombination frequencies. The maximum lod scores and the corresponding recombination frequencies are listed in the last three columns. The data exclude close linkage with a number of loci, including three of four tested on chromosome 1 .

The lod scores with 12 other genetic markers were inconclusive at all values of $\theta$ (table 2); thus, linkages could be neither excluded nor confirmed. Maximum lod scores and relevant recombination values for these markers are given in the last three columns. Because our results failed to reveal statistically significant evidence of a locus linked to $\mathrm{NF}$, detailed pedigrees with complete marker data are not published but are available from the senior author.

An intriguing preliminary finding was a suggestive

TABLE 1 Statistically significant n?gative lod scores between NF and genetic markers* $\left(\theta_{\mathrm{m}}=\theta_{i}\right)$.

\begin{tabular}{|c|c|c|c|c|c|c|c|c|c|c|c|}
\hline \multirow[t]{2}{*}{ Markert } & \multirow[t]{2}{*}{ Chromosomet } & \multirow{2}{*}{$\begin{array}{l}\text { No of } \\
\text { families }\end{array}$} & \multirow[t]{2}{*}{$0=0.01$} & \multirow[t]{2}{*}{0.05} & \multirow[t]{2}{*}{$0 \cdot 1$} & \multirow[t]{2}{*}{$0 \cdot 2$} & \multirow[t]{2}{*}{$0 \cdot 3$} & \multirow[t]{2}{*}{$0 \cdot 4$} & \multicolumn{3}{|c|}{ Maximum, $\theta_{\mathrm{m}}=\theta_{\mathrm{f}} \S$} \\
\hline & & & & & & & & & $Z$ & $\boldsymbol{\theta}_{\mathrm{m}}$ & $\theta_{p}$ \\
\hline $\mathbf{R h}$ & 1 & 10 & -9.7 & $-4 \cdot 6$ & -2.4 & -0.7 & $-0 \cdot 1$ & 0.0 & 0.4 & 0.4 & 0.1 \\
\hline $\mathrm{PGM}_{1}$ & 1 & 11 & -6.9 & $=3 \cdot 3$ & $-1 \cdot 6$ & -0.3 & 0.2 & 0.2 & 0.24 & 0.3 & 0.4 \\
\hline Fy & 1 & 10 & -17.4 & $-10 \cdot 5$ & -6.8 & $-3 \cdot 2$ & $-1 \cdot 4$ & -0.4 & & & \\
\hline Jk & $2 ?$ & 10 & $=2.8$ & $=1 \cdot 3$ & $\overline{-0.6}$ & $\overline{-0.1}$ & -0.0 & -0.0 & $0 \cdot 1$ & 0.4 & $0 \cdot 2$ \\
\hline Kkp & $2 ?$ & 3 & -7.6 & $\overline{-4 \cdot 5}$ & -3.0 & $-1 \cdot 4$ & -0.6 & -0.2 & & & \\
\hline $\mathrm{ACP}_{1}$ & 2 & 9 & $\overline{-7.4}$ & $-4 \cdot 9$ & -3.0 & $-1 \cdot 2$ & -0.4 & -0.04 & & & \\
\hline MNSs & 4 & 11 & -15.9 & $\overline{-9.6}$ & $\overline{-6 \cdot 2}$ & $-3 \cdot 0$ & $-1 \cdot 5$ & -0.6 & & & \\
\hline HLA & 6 & 6 & $-8 \cdot 2$ & $\overline{-3 \cdot 3}$ & $\overline{-1 \cdot 4}$ & $\overline{0.0}$ & 0.4 & 0.3 & 0.4 & 0.4 & 0.3 \\
\hline BF & 6 & 8 & $\overline{-3 \cdot 8}$ & $\overline{-2 \cdot 1}$ & $-1 \cdot 3$ & -0.6 & -0.3 & $-0 \cdot 1$ & & & \\
\hline $\mathrm{GLO}_{1}$ & 6 & 9 & $\overline{-7.4}$ & $\overline{-5 \cdot 1}$ & $-3 \cdot 6$ & $-1 \cdot 7$ & -0.8 & -0.3 & & & \\
\hline $\mathrm{ABO}$ & 9 & 11 & $=-15 \cdot 2$ & $\overline{-8 \cdot 3}$ & $\overline{-5 \cdot 14}$ & -2.3 & $-1 \cdot 0$ & $-0 \cdot 3$ & & & \\
\hline GPT & $10 ?$ & 10 & -6.6 & $\overline{-3 \cdot 8}$ & $-2 \cdot 2$ & $\overline{-0.9}$ & -0.4 & -0.2 & & & \\
\hline EsD & 13 & 8 & $-6 \cdot 1$ & $-4 \cdot 5$ & -3.2 & $-1 \cdot 8$ & $-1 \cdot 0$ & -0.4 & & & \\
\hline HP & 16 & 11 & $\overline{-3 \cdot 1}$ & $-1 \cdot 2$ & $\overline{-0.5}$ & 0.0 & $0 \cdot 1$ & 0.1 & 0.7 & 0.4 & 0.01 \\
\hline PGP & 16 & 8 & -4.9 & $=2.8$ & $-1 \cdot 5$ & -0.4 & 0.0 & 0.1 & 0.4 & 0.4 & 0.05 \\
\hline $\mathbf{P}$ & $?$ & 5 & $\overline{-2 \cdot 1}$ & $\overline{-0.7}$ & -0.3 & -0.1 & 0.1 & 0.0 & 0.1 & 0.2 & 0.4 \\
\hline
\end{tabular}

*Underlined scores $(\leq-2 \cdot 0)$ indicate linkage excluded at that value of recombination.

+Gene symbols are those used by the Human Gene Mapping Conference, Oslo, 1982 (Cytogenet Cell Genet 1982;32).

$¥$ Chromosome to which marker locus is assigned if assignment is confirmed.

$\S \mathrm{Ma}$ ximum lod score, if a positive maximum occurred. 
TABLE 2 Genetic markers with inconclusive lod scores $(-2 \cdot 0<Z<+3 \cdot 0)$.

\begin{tabular}{|c|c|c|c|c|}
\hline Marker* & Chromosome† & No of families & Minimum lod score $\left(\theta_{m}, \theta_{p}\right)$ & Maximum lod score $\left(\theta_{m}, \theta_{t}\right)$ \\
\hline $\begin{array}{l}\text { AMY, } \\
\text { TF } \\
\text { GC } \\
\text { AK } 1 \\
\text { GALT } \\
\text { GM } \\
\text { PI } \\
\text { Le } \\
\text { Se } \\
\text { ADA } \\
\text { E1 } \\
\text { PTC }\end{array}$ & $\begin{array}{l}1 \\
3 \\
4 \\
9 \\
9 \\
14 \\
14 \\
19 ? \\
19 ? \\
20 \\
? \\
?\end{array}$ & $\begin{array}{l}3 \\
1 \\
6 \\
4 \\
5 \\
1 \\
3 \\
9 \\
9 \\
4 \\
3 \\
1\end{array}$ & $\begin{array}{l}-0.02(0.01,0.01) \\
0.00 \\
-1.92(0.4,0.01) \\
-0.93(0.01,0.01) \\
-1.17(0.01,0.01) \\
-1.41(0.01,0.01) \\
-0.29(0.01,0.01) \\
-0.15(0.4,0.01) \\
-1.63(0.01,0.4) \\
-1.63(0.01,0.01) \\
-1.11(0.01,0.01) \\
0.00\end{array}$ & $\begin{array}{l}0.74(0.1,0.4) \\
0.00 \\
0.89(0.03,0.3) \\
0.07(0.3,0.4) \\
0.56(0.4,0.01) \\
-0.02(0.4,0.4) \\
0.51(0.2,0.4) \\
0.05(0.01,0.4) \\
0.64(0.4,0.01) \\
0.46(0.2,0.4) \\
0.03(0.4,0.2) \\
0.00\end{array}$ \\
\hline
\end{tabular}

*Gene symbols are those used by the Human Gene Mapping Conference, Oslo, 1982 (Cytogenet Cell Genet 1982;32).

†Chromosome to which marker is assigned.

lod score of $+2 \cdot 2$ when the first five informative families were analysed for linkage with $\mathrm{GC}$, assigned to the proximal region of chromosome 4. However, the sixth informative family gave negative scores, resulting in a combined maximum lod score of only $0.89\left(\theta_{\mathrm{m}}=0.03, \theta_{\mathrm{f}}=0.28\right)$. The other five families were not informative for GC.

In the absence of statistically significant evidence for linkage between NF and GC, we chose to test for linkage and genetic heterogeneity simultaneously using the suggestion of $\mathrm{Smith}^{12}$ as implemented by Hodge et $_{\text {al }}{ }^{13}$ for $\mathrm{H}_{0}: \theta=0 \cdot 5, \alpha=1$, where $\alpha$ is the proportion of families with the two markers linked. The test statistic is the log likelihood (L) ratio, denoted lod2:

$$
\operatorname{lod} 2=\log _{10}\left\{\begin{array}{l}
\max \\
\theta, \alpha \\
[L(\theta, \alpha)] / L(0 \cdot 5,1)\} .
\end{array}\right.
$$

A value of 3.0 is required for statistical significance. In our six informative families, the lod 2 was $1 \cdot 3$, at $\alpha=0 \cdot 70, \theta=0.01$.

\section{Discussion}

Linkage studies with NF present several problems. Establishing that a subject has NF can be difficult. The diagnosis rests solely on clinical findings because there is no laboratory marker for the disorder except pathological confirmation of multiple neurofibromas. Occasional subjects may have insufficient clinical features of NF (for example, two café-au-lait spots and one neurofibroma) to assign an unequivocal diagnosis according to present clinical criteria. ${ }^{1}$ Young children may be particularly difficult to classify since café-au-lait spots typically develop during the first few years of life, ${ }^{1}$ and neurofibromas do not commonly appear until puberty or later. Furthermore, one or two café-au-lait spots are said to occur in about $10 \%$ of the normal population and one or two neurofibromas (excluding the plexiform type) can apparently appear in the absence of NF. ${ }^{1}$
Another problem results from the remarkable clinical heterogeneity demonstrated by persons with the disease. Clinical manifestations of NF, even in unequivocal cases, may vary among families, between generations of a single family, among sibs, and even between identical twins. ${ }^{14} 15$ In addition, in about half of all cases, neither parent can be shown to be affected. These sporadic cases have been attributed to new spontaneous mutations. NF is said to be the most common newly occurring dominant mutation in the human population. ${ }^{1}$ Some of the clinical diversity of NF and its high frequency and mutation rate might be explained if NF resulted from mutation at more than one locus.

No study, including the present one, has found conclusive evidence for genetic linkage of NF. The possible linkage of NF with typical autosomal dominant myotonic dystrophy (MD) was suggested in a report of one family with both disorders. ${ }^{2}$ However, the phenotypes of the parents in the first generation with respect to MD were not known with certainty. One interpretation of the phenotypes leads to the conclusion of close linkage between NF and MD, while the other interpretation produces no evidence for linkage. No-one in our 11 families had MD. However, we examined the possibility of linkage of NF with the secretor locus, which is closely linked to MD. ${ }^{16}$ Our maximum lod score of 0.6 at $\theta_{\mathrm{m}}=0.4, \theta_{\mathrm{f}}=0.01$ provides no evidence for linkage.

Our results and those of a previous study ${ }^{3}$ also eliminate the possibility of close linkage with HLA. Our maximum lod score of 0.35 at $\theta_{\mathrm{m}}=0.4$, $\theta_{\mathrm{f}}=0.3$ would be negated by the scores in their paper, although an exact interpolation of their lod score value for a penetrance of $95 \%$ cannot be made.

An intriguing finding in our study was a lod score of +2.2 when the first five informative families were analysed for linkage with GC. However, the one other informative family gave completely negative scores so that the maximum lod score for all six families was only 0.89 at $\theta_{\mathrm{m}}=0.03, \theta_{\mathrm{f}}=0.28$.

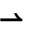


This type of result would indicate genetic heterogeneity if statistical significance were achieved, but, in its absence, represents merely an interesting observation.

The need to develop a reliable diagnostic laboratory test for both sporadic and familial NF cannot be overstated. Peripheral NF could then be distinguished from disorders with overlapping features, including 'central' NF. Subjects, especially children, with minimal, partial, or even no features of NF could be assigned an accurate diagnosis early in life and offered appropriate counselling. Early diagnosis could lead to improved monitoring of affected persons for potentially treatable complications, such as scoliosis. Persons who did not inherit the gene could also obtain this information at a much earlier age than is now possible. Antenatal diagnosis could also be provided for affected families.

In the absence of a laboratory test for NF, use of a linked genetic marker could accomplish most of these clinical goals. Furthermore, after the gene has been mapped, identification of the mutation(s) would provide important new avenues to investigate pathogenesis, clinical heterogeneity, the nature of the defective gene product, potential treatments, and explanations for the high sporadic mutation rate. Although our attempt to establish linkage between NF and a series of genetic markers was not successful, we encourage others to undertake linkage analysis of their large NF kindreds.

We are indebted to Maryellen Sparkes and Michol Crist for laboratory assistance, to Jane Chen, Kamton Joe, and Melanie Ashe for technical assistance with the computer analysis, and to Dr John J Mulvihill for helpful suggestions on the manuscript. This research was supported in part by grants No HD-0732, HD-05615, and HD-4612 from the National Institutes of Child Health and Human Development, NIH, by Interagency Agreement No Y01-CP-00502 with the Naval Medical Research Institute, NMRI, and Uniformed Services University of the Health Sciences, Bethesda, Maryland, and a private donation from $\mathrm{Mr}$ and Mrs Arthur Golden in memory of Margaret Helen Weston. Appreciation is expressed to $\mathrm{Dr}$ Brigid Leventhal, Pediatric Oncology Division, Johns Hopkins Hospital, for referring the proband in family NCI 1169.

\section{References}

1 Crowe EW, Schull WJ, Neel JV. A clinical, pathological, and genetic study of multiple neurofibromatosis. Springfield, Illinois: Thomas, 1956.

${ }^{2}$ Ichikawa K, Crosley CJ, Culebras A, Weitkamp L. Coincidence of neurofibromatosis and myotonic dystrophy in a kindred. $J$ Med Genet $1981 ; 18: 134-8$.

3 Lepage V, Tongio MM, Mayer S, et al. Neurofibromatosis (von Recklinghausen's disease). In: Terasaki PI, ed. Histocompatibility testing 1980. Los Angeles, California: UCLA Tissue Typing Laboratory, 1981:719-21.

4 Eldridge R. Central neurofibromatosis with bilateral acoustic neuroma. In: Riccardi VM, Mulvihill JJ, eds. Neurofibromatosis (von Recklinghausen disease): genetics, cell biology, and biochemistry. New York: Raven Press, $1981: 57-65$.

5 Crandall BF, Spence MA. Linkage relations of the phenylcarbamide locus (PTC). Hum Hered 1974;24: 247-52.

6 Hodge SE, Spence MA, Crandall BF, et al. Huntington disease: linkage analysis with age of onset corrections. Am J Med Genet 1980;5:247-54.

7 Robertson RD, Spence MA, Sparkes RS, Neiswanger K, Field LL. Linkage analysis with trismus-pseudocamptodactyly syndrome. Am J Med Genet 1982;12:115-20.

8 Dykes D, Polesky H, Cox E. Isoelectric focusing of GC (vitamin D binding globulin) in parentage testing. Hum Genet $1981 ; 58: 174-5$.

9 Race RR, Sanger R. Blood groups in man. Oxford: Blackwell Scientific Publications, 1975:326-7.

10 Carey JC, Laub JM, Hall BD. Penetrance and variability in neurofibromatosis: a genetic study of 60 families. Birth Defects 1979;15(5B):271-81.

11 Ott J. Estimation of the recombination fraction in human pedigrees: efficient computation of the likelihood for human linkage studies. Am J Hum Genet 1974;26:588-97.

12 Smith CAB. Testing for heterogeneity of recombination fraction values in human genetics. Ann Hum Genet $1963 ; 27: 175-82$.

13 Hodge SE, Anderson CE, Neiswanger K, Sparkes RS, Rimoin DL. The search for heterogeneity in insulindependent diabetes mellitus (IDDM): linkage studies, two-locus models, and genetic heterogeneity. Am J Hum Genet (in press).

14 Riccardi VM, Kleiner B, Lubs ML. Neurofibromatosis: variable expression is not intrinsic to the mutant gene. Birth Defects 1979;15(5B):283-9.

15 Bader JL, Rubenstein AE. Disseminated neurofibromatosis in one of two monozygotic twins (abst). Neurology (Minneap) $1981 ; 31: 98$.

16 Renwick JH, Bundey SE, Ferguson-Smith MA, Izatt MM. Confirmation of linkage of the loci for myotonic dystrophy and ABH secretion. J Med Genet 1971;8:407-16.

Correspondence and requests for reprints to Dr M A Spence, Division of Medical Genetics, Neuropsychiatric Institute, Center for the Health Sciences, Los Angeles, California 90024, USA. 